\title{
Effect of Calcium Aluminate Cement Variety on the Hydration of Portland Cement in Blended System
}

\author{
XU Linglin",2, WA VG Peiming ${ }^{1,2 *}$, Geert DE SCHU'TTER³, WU Guangming, \\ (1.School of Materials Science and Engineering, Tongji University, Shanghai 201804, China; 2.Key Laboratory of Advanced Civil \\ Engineering Materials, Ministry of Education, Tongji University, Shanghai 201804, China; 3.Magnel Laboratory for Concrete Research, \\ Faculty of Engineering, Ghent University, Belgium)
}

\begin{abstract}
Two kinds of CACs with different monocalcium aluminate (CA) contents were used in the $\mathrm{PC} / \mathrm{CAC}$ (PAC) mixtures. Effects of CA and CACs on the properties of PAC were analyzed by setting times and the compressive strength tests, and also by means of calorimetry, XRD, DTA-TG and ESEM. The experimental results show that the compressive strength of the PAC mortars decreases with increasing content of CAC while it declines sharply with a higher content of CA in CAC. Compared with neat PC paste, the content of calcium hydroxide in hydrates of PAC paste decreases significantly, and the hydration time of PC is prominently prolonged. Additionally, the higher the content of CA in CAC, the more obviously the hydration of $\mathrm{PC}$ is delayed, confirming that the CA phase in CAC plays an important role in the delay of PC hydration.
\end{abstract}

Key words: calcium aluminate cement; Portland cement; hydration; delay; monocalcium aluminate $(\mathrm{CA})$

\section{Introduction}

CAC is well known as an indispensable material in the construction field for its high early strength even at low temperature and resistance to chemical attack ${ }^{[1]}$, which makes it usually use in special applications where the performance of $\mathrm{PC}$ is insufficient. But the usage of CAC is greatly limited for its phase transition at higher temperature, which results in the decline of later strength ${ }^{[2,3]}$. The annual production of CAC is very small compared with $\mathrm{PC}$, and $\mathrm{CAC}$ can not directly replace $\mathrm{PC}$ in daily applications. Therefore, it is widely used in combination with PC and calcium sulfate ${ }^{[4-15]}$. In those formulations, CAC mainly contributes to a wide range of properties such as rapid setting and hardening, controlled expansion and shrinkage compensation.

Although it is well known that CAC is added

CWuhan University of Technology and SpringerVerlag Berlin Heidelberg 2014

(Received: Oct. 19, 2013; Accepted: Jan. 8, 2014)

XU Linglin (徐玲琳): Ph D; E-mail: xulinglin@126.com

*Corresponding author: WANG Peiming (王培铭): Prof:;Ph D; E-mail: tjwpm@126.com

Funded by the National Key Technology R\&D Programs in the 12th Five-year Plan of China (2012BA20B02) into PC to accelerate setting and hardening ${ }^{[2,6,7,12,16]}$, the replacement of PC with $\mathrm{CAC}$ has been found to be detrimental to the compressive strength especially at later age $\mathrm{e}^{[7,10,17]}$, which becomes a barrier for the application of PAC mixtures. The addition of CAC delayed the hydration of $\mathrm{PC}^{[7,12]}$, which may result from the film-like hydration products which surrounded anhydrate granules at early age, however, with no clear evidence to prove it. Therefore, it is of prime importance to explore the underlying hydration mechanism of the PAC mixtures. Additionally, the commercial variety of CAC is totally different, especially on the content of the main phase CA, which results from the difference in production technology (melting method or calcination method) and the grade of raw material, so the choice of CAC in application becomes another key issue. According to literatures, there is an obvious lack of concerning investigations, so the hydration of PAC was further investigated and two kinds of CACs with different content of CA were compared in the present paper.

The calorimetric measurement is a well established method to study the kinetics and mechanism of hydration in cementitious materials ${ }^{[18]}$ since it shows great versatility in studying the hydration 
Table 1 Chemical compositions of the cements determined by XRF/wt $\%$

\begin{tabular}{cccccccccc}
\hline Cement & $\mathrm{SiO}_{2}$ & $\mathrm{CaO}$ & $\mathrm{Al}_{2} \mathrm{O}_{3}$ & $\mathrm{Fe}_{2} \mathrm{O}_{3}$ & $\mathrm{MgO}$ & $\mathrm{SO}_{3}$ & $\mathrm{~K}_{2} \mathrm{O}$ & $\mathrm{Na}_{2} \mathrm{O}$ \\
\hline $\mathrm{PC}$ & 21.50 & 65.20 & 4.14 & 2.40 & 2.57 & 2.89 & 0.84 & 0.67 \\
$\mathrm{~A}$ & 4.43 & 38.90 & 39.40 & 13.70 & 0.60 & 0.10 & 0.13 & - \\
$\mathrm{B}$ & 0.34 & 31.20 & 67.10 & 0.10 & - & 0.06 & - & 0.34 \\
\hline
\end{tabular}

kinetics of cementitious systems and helps to monitor cement-admixture combinations with respect to the hydration process ${ }^{[9,19-23]}$. In addition, compared with widely used SEM, the sample preparation of ESEM has no destruction on the original microstructure, so it enables the more reliable observation of microstructure. Therefore, the calorimetry and ESEM, supplemented by other standard measurements such as XRD and DTA-TG, were used to investigate the effect of CAC variety on the hydration process of PAC mixtures.

\section{Experimental}

\subsection{Cement}

Portland cement (PC) (CEM I 42.5) and two varieties of CACs (hereafter named A and B separately) used were obtained from Lafarge Cement Co. and Kerneos cement Co,, respectively. The chemical composition of the cements was determined by X-ray fluorescence (XRF), as listed in Table 1.

\subsection{Mix proportions}

Table 2 Mix proportions/wt $\%$

\begin{tabular}{|c|c|c|c|c|c|}
\hline & PC & A & & PC & B \\
\hline A1 & 97 & 3 & B 1 & 97 & 3 \\
\hline A2 & 94 & 6 & B2 & 94 & 6 \\
\hline A3 & 91 & 9 & B3 & 91 & 9 \\
\hline A4 & 88 & 12 & B4 & 88 & 12 \\
\hline A5 & 85 & 15 & B5 & 85 & 15 \\
\hline
\end{tabular}

As shown in Table 2, the PAC pastes were prepared by mixing two kinds of CACs in amounts of $3 \%, 6 \%, 9 \%, 12 \%$ and $15 \%$ by mass of PC respectively, and $\mathrm{S} 0$ refers to the pure $\mathrm{PC}$. The water to cement ratio was 0.5 by mass. Mortar prisms (40 $\mathrm{mm} \times 40 \mathrm{~mm} \times 160 \mathrm{~mm}$ ) were prepared according to GB/T 17671-1999 using 1350 g ISO standard quartz aggregate per $450 \mathrm{~g}$ cement.

\subsection{Curing and testing}

The setting time of PAC pastes was determined according to ASTMC191 using a Vicat apparatus at $20{ }^{\circ} \mathrm{C}$. The specimens were demoulded after 24 hours curing at $20 \pm 1{ }^{\circ} \mathrm{C}$ with a relative humidity of $60 \% \pm 10 \%$. And the mechanical tests were performed at certain curing ages ( 3 and 28 days). Compressive strength of mortars was measured according to GB/T 17671-1999. The standard deviation less than 15\% with respect to the mean was applied in the analysis.

An isothermal heat-conduction calorimeter (TAM air C80, Thermometric, Sweden) was used to measure the hydration heat evolution of the binders. The water to binders ratio was 0.5 and the experimental temperature was $20 \pm 0.1{ }^{\circ} \mathrm{C}$. Binders and water were tempered for several hours before mixing, then the water was injected into the reaction vessel and the samples were stirred in the calorimeter for several minutes. This procedure allowed monitoring the heat evolution from the very beginning when water was added to the binders. Data logging was continued up to 7 days.

Freshly fractured surfaces were examined by ESEM (FEI, QUANTA 200) using the low vacuum mode (at 1 Torr $\mathrm{H}_{2} \mathrm{O}$ ). The polished samples were prepared by epoxy resin impregnating, polishing and carbon coating. BSE images of the polished samples were used to estimate the porosity based on image analysis using the different grey levels under high vacuum mode (at $1 \mathrm{E}-5$ Torr $\mathrm{H}_{2} \mathrm{O}$ ). The solid fractions of the blended cement pastes were crushed and ground in acetone, dried at curing temperature and then used for XRD and DTA-TG analyses. The XRD data were recorded using a Rigaku-D/max2550VB3+ instrument. Scanning was performed between $5^{\circ}$ and $75^{\circ}$ with a $2 \theta$ increment of $2^{\circ} / \mathrm{min}$, and a $\mathrm{Cu} \mathrm{K} \alpha$ radiation $(\lambda=1.54$ $\AA$ ). In addition, an accelerating voltage of $40 \mathrm{kV}$ and a current of $100 \mathrm{~mA}$ were selected. DTA-TG analyses were performed with a simultaneous thermal analyzer (NETSCH, STA 449 C Jupiter), where about $10 \mathrm{mg}$ of hydrated sample was placed in an open vessel in $\mathrm{N}_{2}$ atmosphere, and investigated at a heating rate of $10{ }^{\circ} \mathrm{C} /$ min up to $1050{ }^{\circ} \mathrm{C}$.

\section{Results and discussion}

\subsection{Setting time}

The setting time of PAC is given as the function of the dosage of CAC in Fig.1. Both initial and final setting time of PAC are shortened with increasing dosage of CAC. The CAC content at a replacement 
level below $6 \%$ has little effect on the initial and final setting time; while both initial and final setting time decreases sharply when the CAC content is higher than $6 \%$, and rapid setting even occurs in the A5 and B5 pastes.

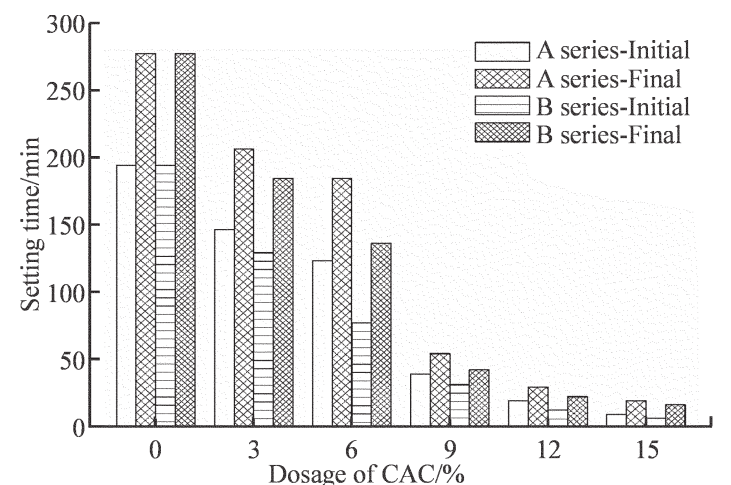

Fig.1 Relationships between setting times of PAC and dosage of CAC

It also can be observed that both initial and final setting time of the PAC with higher content of CA (B series) are shorter than that of A series. The microstructure of B series paste develops very quickly once in contact with water, which may result from the quick formation of ettringite, alumina gel and hydrated calcium aluminate. But $\mathrm{Gu}$ et al indicated that the rapid setting of PAC only resulted from the quick formation of ettringite ${ }^{[7,9]}$. In addition, Scrivener et al demonstrated that hydrates of PC were mainly deposited around unhydrated cement grains, while those of CAC were evenly distributed throughout space ${ }^{[24]}$. When they were blended, the main phases in CAC such as CA reacted with water rapidly and thus alumina gel and pellicle-like hydrated calcium aluminate formed, so the connectivity of the paste decreased quickly. As a result, both initial and final setting time was shortened, and the PAC with higher CA set more rapidly.

\subsection{Strength development}

Fig. 2 shows the relationship between compressive strength of the PAC mortars and the dosage of CAC obtained after 3 days and 28 days. In general, the compressive strength of the PAC mortars is less than that of PC mortar. For instance, the 28-day strength of B3 mortar is only $62 \%$ of that of S0. Additionally, it firstly increases slightly and then decreases greatly with increasing CAC content, reaching a maximum value at a $\mathrm{CAC}$ content of $6 \%$. As hydration time increases, the effect of CAC content on the compressive strength of PAC mortars diminishes, especially when the CAC content is higher than $6 \%$.

After 3 days of hydration, the compressive strengths of the A series mortars are much higher than that of B series. However, this situation does not prevail as hydration time increases. The compressive strengths of the A series mortars improve little from 3 days to 28 days, while that of B series mortars grows gradually and even exceeds that of A series after 28 days when the CAC dosage is $3 \%$ and $6 \%$, indicating that the increasing content of CA phase in PAC mixtures declines the early strength of cement mortar significantly, but has less effect on the later strength.

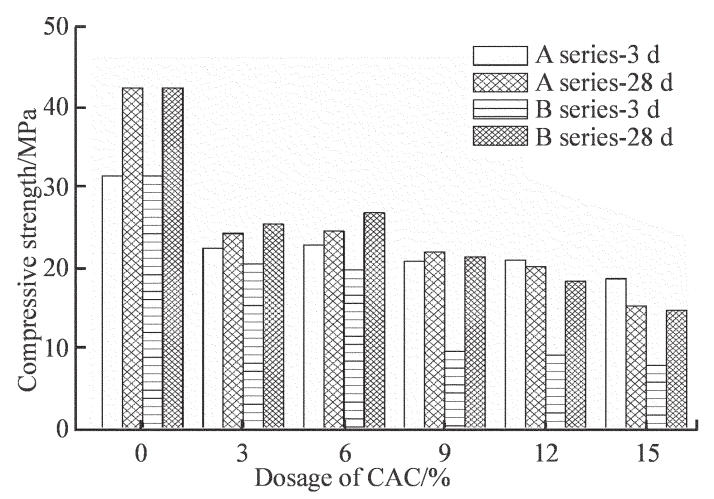

Fig.2 Relationships between compressive strength of PAC mortars and dosage of CAC

\subsection{Hydration}

\subsubsection{Rate of heat evolution}

The curves for the rate of heat evolution of A5 and B5 exhibit a heat evolution profile similar to that of neat PC paste (Fig.3). According to the Taylor's theory on cement chemistry ${ }^{[2]}$, the first exothermic peak in the heat evolution curve of PC results from complex reactions during the wetting process. The second exothermic peak can be attributed to the $\mathrm{C}_{3} \mathrm{~S}$ and/or $\mathrm{C}_{2} \mathrm{~S}$ hydration. In addition, the third exothermic peak (if present) results from the transition from ettringite to monosulfate. Compared with the curve of PC (S0), there is a significant delay in the appearance of the second peak for the curve of A5 and B5. The so-called induction period associated with $\mathrm{S} 0$ paste is about $2 \mathrm{~h}$. However, it is much longer for A5 and B5. The maximum values of the heat evolution rate for $\mathrm{S} 0$, A5 and B5 pastes are 2.71, 1.77 and $1.54 \mathrm{~mW} \cdot \mathrm{g}^{-1}$, and the corresponding time is $13.08,54.40$ and 62.34 $\mathrm{h}$, respectively. It means that the hydration of $\mathrm{PC}$ is significantly delayed with CAC addition. This finding is consistent with the findings of Gu et $a l^{[7,9]}$ and Gawlicki et $a l^{[25]}$ who stated that this long dormant period may result from a surface coverage of the clinker grains by early hydration of CAC.

Moreover, it can also be concluded from Fig.3 that the hydration of PC is more obviously delayed 
by $\mathrm{B}$ series than A series, which indicates that the hydration of PAC is sensitive to CA content. A higher content of CA slows down the hydration of PC more seriously. As a result, the 3 -days compressive strength of B series is much lower than that of A series, which is consistent with the results obtained from Fig.2.

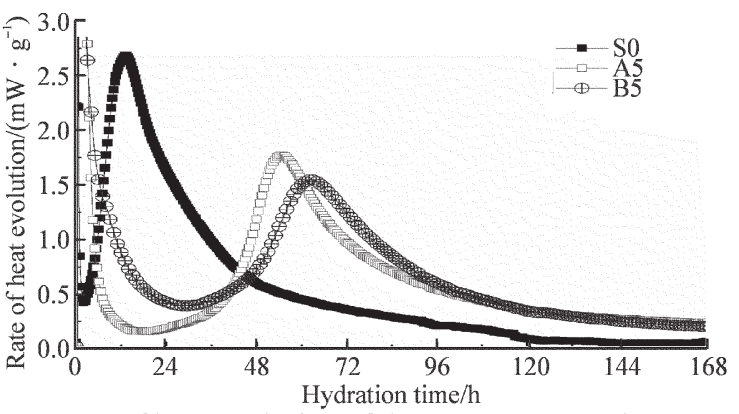

Fig.3 Rate of heat evolution of the pure S0, A5 and B5 pastes

\subsubsection{Phase composition}

From the XRD patterns of PAC pastes obtained after 3 days of hydration (Fig.4), both calcium hydroxide $(\mathrm{CH})$ and ettringite formed in the hydrates. Notably, the amount of $\mathrm{CH}$ in A5 hydrates was much lower than that of S0. Additionally, a small peak around $10^{\circ}$ in the pattern of A5 indicates that calcium aluminate hydrate formed.

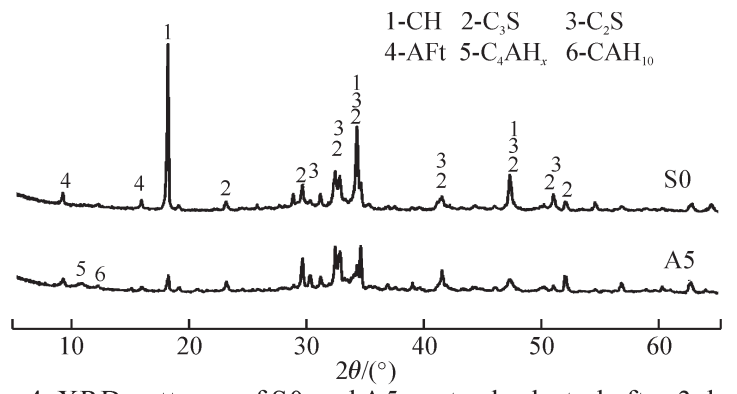

Fig. 4 XRD patterns of S 0 and A 5 pastes hydrated after 3 days

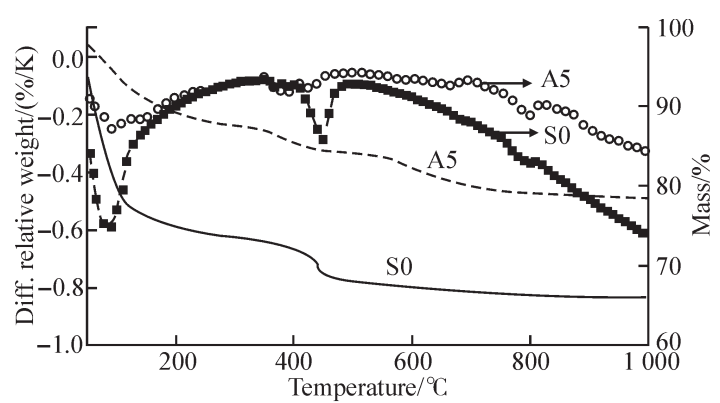

Fig. 5 DTA-TG curves of S0 and A5 pastes hydrated after 3 days

$\mathrm{CH}$ is one major phase of PC hydrates, and the amount of $\mathrm{CH}$ reflects the overall hydration degree of clinker. The DTA-TG data (Fig.5) indicate that the $\mathrm{CH}$ content in hydrates of $\mathrm{S} 0$ and $\mathrm{A} 5$ pastes after 3 days is $14.1 \%$ and $3.7 \%$, respectively. It means that the PC in PAC has a much lower degree of hydration, which is confirmed by the XRD patterns shown in Fig.4. Additionally, the $\mathrm{CH}$ content in hydrates is not consistent with the weight ratio of $\mathrm{PC}$ in PAC. The PC content in the unhydrated A5 paste is $85 \%$ of that in the unhydrated $\mathrm{S} 0$, but the $\mathrm{CH}$ amount in the $\mathrm{A} 5$ paste is only $26 \%$ of that in the S0 paste after 3 days of hydration. This further suggests that the hydration of $\mathrm{PC}$ is delayed by CAC, which is in agreement with the findings of $\mathrm{Gu}$ et $a l^{[7]}$.

\subsubsection{Morphology}

The ESEM images show clearly that film-like hydrates cover the unhydrated granules of A5 and B5 paste hydrated after 3 days (Fig.6(b) and Fig.6(c)), which is more obvious in the B5 paste at higher magnification factor in Fig.6(d). However, instead of such film-like hydrates, only ettringite and $\mathrm{C}-\mathrm{S}-\mathrm{H}$ gel are clearly observed in the S0 paste (Fig.6(a)). Additionally, comparing Fig.6(b) with Fig.6(c), it can also be concluded that a higher content of CA in paste contributes to an obvious increase in the formation of film-like hydrates.
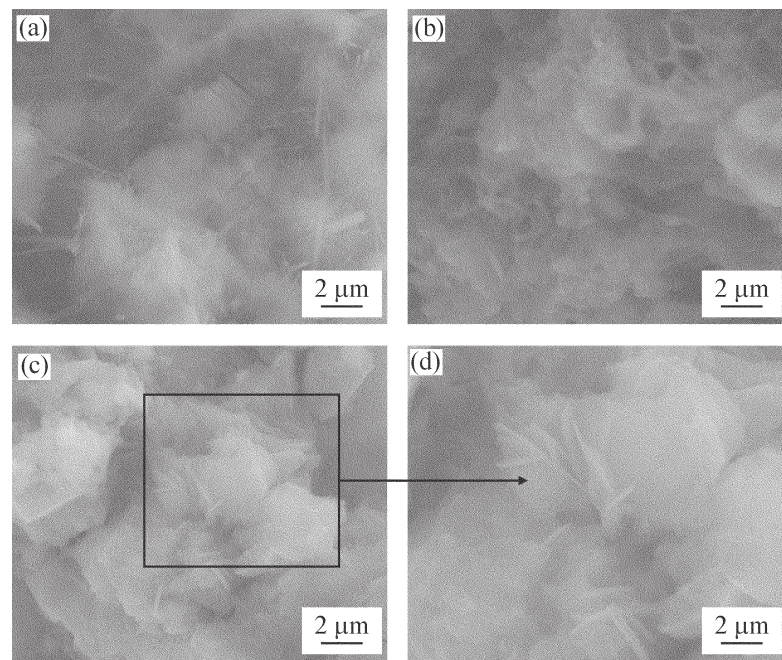

Fig.6 ESEM images of pastes after 3 days: (a) S0 paste; (b) A5 paste; (c) B5 paste; (d) B5 paste

The protective layer hypothesis has been widely accepted by many researchers, who postulates that a hydrate forms fitting closely on the surface of $\mathrm{C} 3 \mathrm{~S}$ and hydration restarts when this hydrated layer is removed or converted, but no evidence has been given up to now. The ESEM is used in this paper to avoid the destruction on the sample during sample preparation. As can be seen from Fig.6, the layer which forms in the hydrates of PAC may delay further hydration of PC, and directly leads to the reduction of compressive strength (Fig.2) and the delay in heat evolution of PAC (Fig.3). The film-like hydrates in B5 paste are more 
pronounced than those in A5 paste, so the hydration is delayed more seriously.

To characterize the chemical composition of the membrane, energy dispersive spectroscopy (EDS) was also applied. However, because the film-like hydrates are very thin and irregular, it is difficult to determine them even at low acceleration voltage, so further study is necessary. But the deduction, which the delay of PC hydration only results from the formation of ettringite crystals which surround the anhydrate granules at early age, is not universal. Palou $\mathrm{MT}^{[26]}$ found that $\mathrm{Al}^{3+}$ delayed the hydration of $\mathrm{PC}$, which may result from the formation of alumina gel. Such semi-permeable membrane broke until the concentration of $\mathrm{Ca}^{2+}$ and $\mathrm{OH}^{-}$was higher enough and then the hydrates such as ettringite and $\mathrm{CH}$ precipitated, which seems more reasonable.
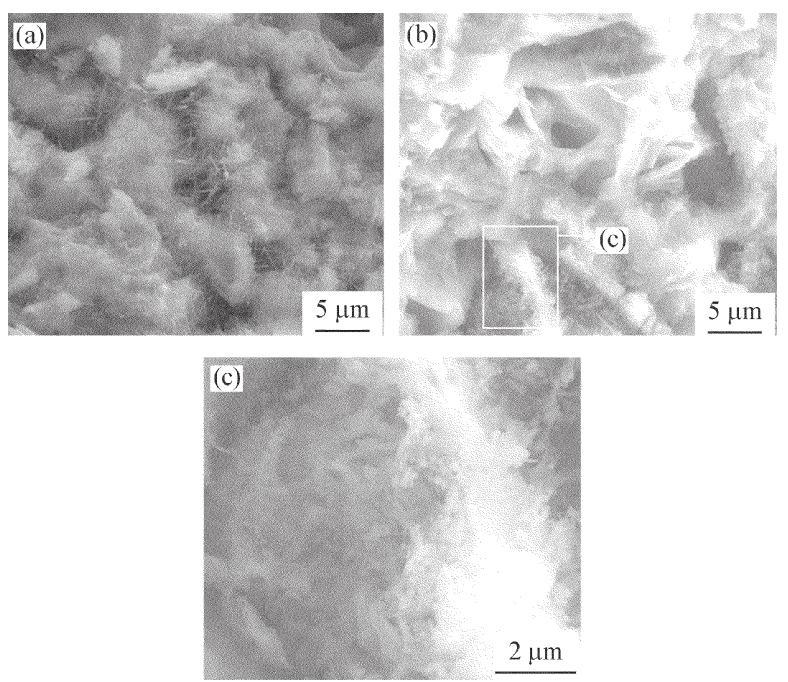

Fig. 7 ESEM images of pastes after 28 days: (a) S0 paste; (b) A5 paste; (c) A5 paste

After 28 days of hydration, the hydrates such as C-S-H gel, $\mathrm{CH}$ and ettringite fill the granules and voids in S0 paste (Fig.7(a)) and form a spatial network with unhydrated grains. Instead, many coarse pores are generated (Fig.7(b)) and the calcium alumina hydrates such as $\mathrm{C}_{3} \mathrm{AH}_{6}$ form in $\mathrm{A} 5$ paste (Fig.7 (c)). Therefore, the strength of PAC mortar decreases compared with that of PC mortar.

\subsection{Discussion}

When PC is blended with CAC, the mechanical strength of the binary system mortar (especially the 3 -day strength) is significantly reduced, which is mainly caused by the following three aspects: on the one hand, PAC sets rapidly for these with higher content of $\mathrm{CAC}$, so the hydration products generate
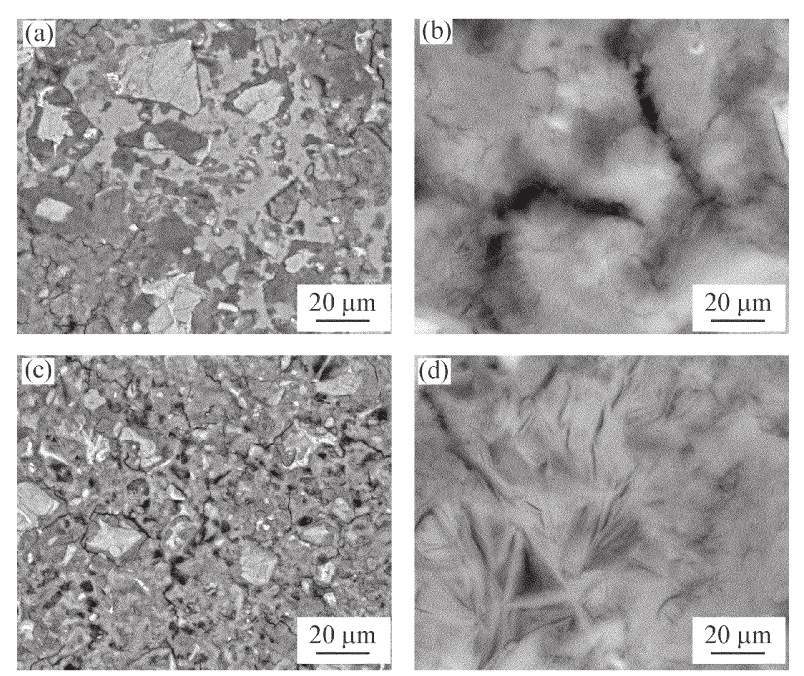

Fig. 8 BSE images of pastes for 28 d: (a) S0; (b) A5

with no time for even dispersion, as a consequence, hydration product deposits on the surface of the unhydrated particles with low filling in pores, which has obviously adverse effects on later hydration; on the other hand, from the aspect of hydration process, the incorporation of CAC significantly leads to longer induction period, thus delays the early hydration of PC; additionally, from the aspect of microstructure of hydration products, a large amount of flake-like hydrated calcium aluminate generates and ettringite transfers to monosulfate because of the lack of sulfate in PAC. As shown in Fig.8(b), those flake-like hydration products between the laps are very loose, so they are vulnerable to crack. In addition, according to the cement chemistry theory ${ }^{[3]}$, solid volume increases by $164 \%$ when ettringite generates, while it increases by $79.2 \%$ when monosulfate generates (the density of ettringite is $1.73 \mathrm{~g} / \mathrm{cm}^{3}$ and the density of monosulfate is $1.80 \mathrm{~g} / \mathrm{cm}^{3}$ ), so if ettringite transfers into monosulfate, the solid volume decreases and porosity increases prominently. Therefore, under the combined effects of the above factors, the 3-day strength of binary system mortar is significantly lower than PC mortar, and the higher the CAC content, the lower the strength, accompanied with greater drying shrinkage at the same time.

\section{Conclusions}

Based on the aforementioned results, the variety of CACs with different CA contents exert a significant influence on the hydration properties of PAC blends. The following conclusions can be drawn from the present work:

a)The compressive strength of PAC mortars 
decreases with increasing content of CAC. Additionally, even with the same dosage of CAC, the higher the content of $\mathrm{CA}$ in $\mathrm{CAC}$, the lower the compressive strength.

b) Compared with PC paste, the content of $\mathrm{CH}$ in hydrates of PAC paste decreases significantly and the appearance of heat evolution from PC is obviously prolonged, which confirms that the hydration of $\mathrm{PC}$ is delayed by the addition of CAC.

c) The CA phase in CAC plays an important role in the delay of $\mathrm{PC}$ hydration. The higher the content of $\mathrm{CA}$ in $\mathrm{CAC}$, the more obviously the hydration of $\mathrm{PC}$ is delayed.

\section{References}

[1] Guan BH, Lou WB, Ye QQ, et al. Calorimetric Study of Calcium Aluminate Cement Blended with Flue Gas Desulfurization Gypsum[J].

J. Therm. Anal. Calorim., 2009, 98(3): 737-742

[2] Taylor HFW. In Cement chemistry(2ed) [M]. London: Thomas Telford, 1997

[3] Peter C Hewlett. In Lea's Chemistry of Cement and Concrete(4 ed)[M] London: Butterworth-Heinemann, 2004: 733-734

[4] Bates PH, Klein AA. Properties of the Calcium Silicates and Calcium Aluminates Occurring in Portland Cement[J]. Journal of the Franklin Institute, 1916, 182(3): 398-401

[5] Fu Y, Ding J, Beaudoin JJ. Expansion Characteristics of a Compounded-expansive Additive and Pre-hydrated High Alumina Cement-based Expansive Additive[J]. Cement Concrete Res., 1995, 25(6): 1 295-1 304

[6] Gu P, Beaudoin JJ. Effect of Lithium Salts on Portland Cement/ High Alumina Cement Paste Hydration[J]. J. Mater. Sci. Lett., 1995, 14(17): $1207-1209$

[7] Gu P, Beaudoin JJ, Quinn EG, et al. Early Strength Development and Hydration of Ordinary Portland Cement Calcium Aluminate Cement Pastes[J]. Advanced Cement Based Materials, 1997, 6(2): 53-58

[8] Gu P, Beaudoin JJ. Lithium Salt-based Additives for Early Strengthenhancement of Ordinary Portland Cement-high Alumina Cement Paste[J]. J. Mater. Sci. Lett., 1997, 16(9): 696-698

[9] Gu P, Beaudoin JJ. A Conduction Calorimetric Study of Early Hydration of Ordinary Portland Cement High Alumina Cement Pastes[J]. Journal of Materials Science, 1997, 32(14): 3 875-3 881

[10] Garces P, Alcocel EG, Andreau CG. Hydration Characteristics of High Alumina Cement/ Portland Cement Mixtures[J]. Zkg Int., 1998, 51(11): 646-649

[11] Kitamura M, Kamitani M, Senna M. Rapid Hardening of Cement by the Addition of a Mechanically Activated $\mathrm{Al}(\mathrm{OH})_{3}-\mathrm{Ca}(\mathrm{OH})_{2}$ Mixture[J]. $J$ Am. Ceram. Soc., 2000, 83(3): 523-527
[12] Amathieu L, Bier A, Scrivener K. Mechanisms of Set Acceleration of Portland Cement Through CAC Addition[C]. In: Int.Conf. on Calcium Aluminate Cement, Edinburgh, 2001:303-317

[13] XU Linglin, WANG Peiming, ZHANG Guofang. Effect of Temperature and Calcium Sulfate Variety on the Hydration of Portland Cement/ Calcium Aluminate Cement Blended Cements[J]. Construction and Building Materials, 2012, (31): 347-352

[14] Sang GC, Liu JP. Study of Properties of Portland and Aluminate Cementitious Composited Grouting Material[J]. Mater. Res. Innov., 2010, 14(3): 200-205

[15] Puri A, Voicu G, Badanoiu A. Expansive Binders in the Portland Cement-calcium Aluminate Cement - Calcium Sulfate System[J]. Rev. Chim-Bucharest, 2010, 61(8): 740-744

[16] Gu P, Fu Y, Xie P, et al. A Study of the Hydration and Setting Behavior of OPC-HAC Pastes[J]. Cement Concrete Res., 1994, 24(4): 682-694

[17] Zhang X, Yang Y, Ong CK. Study of Early Hydration of OPC-HAC Blends by Microwave and Calorimetry Technique[J]. Cement Concrete Res., 1997, 27(9): 1 419-1 428

[18] Bensted J, Barnes P. Structure and Performance of Cements[M]. London and New York: Taylor \& Francis e-Library, 2008

[19] Sauvat N, Sell R, Mougel E, et al. A study of Ordinary Portland Cement Hydration with Wood by Isothermal Calorimetry[J]. Holzforschung, 1999, 53(1): 104-108

[20] Xu L, Wang P, Zhang G. Calorimetric Study on the Influence of Calcium Sulfate on the Hydration of Portland Cement-Calcium Aluminate Cement Mixtures[J]. J. Therm. Anal. Calorim., 2012, (110): $725-731$

[21] Evju C. Initial Hydration of Cementitious Systems Using a Simple Isothermal Calorimeter and Dynamic Correction[J]. J. Therm. Anal. Calorim., 2003, 71(3): 829-840

[22] Pane I, Hansen W. Investigation of Blended Cement Hydration by Isothermal Calorimetry and Thermal Analysis[J]. Cement Concrete Res., 2005, 35(6):1 155-1 164

[23] Ylmen R, Wadso L, Panas I. Insights into Early Hydration of Portland Limestone Cement from Infrared Spectroscopy and Isothermal Calorimetry[J]. Cement Concrete Res., 2010, 40(10): 1 541-1 546

[24] Scrivener KL. In Advanced Concrete Technology: Constituent Materials[M]. Oxford: Elsevier, 2003:26-29

[25] Gawlicki M, Nocun-Wczelik W, Bak L. Calorimetry in the Studies of Cement Hydration[J]. J.Therm. Anal. Calorim., 2010, 100(2): 571-576

[26] Palou MT, Majling J. Effects of Sulphate, Calcium and Aluminum Ions Upon the Hydration of Sulphoaluminate Belite Cement[J]. J. Therm. Anal., 1996, 46(2): 549-556 